\title{
A Viscosity Approximation Method for the Split Feasibility Problems in Hilbert Space
}

\author{
Li Yang $^{1}$ \\ ${ }^{1}$ College of Mathematics and Information, China West Normal University, China \\ Correspondence: Li Yang, College of Mathematics and Information, China West Normal University, Nanchong, Sichuan, \\ 637009, China. E-mail: yangli@ cwnu.edu.cn
}

Received: November 8, 2016 Accepted: December 30, 2016 Online Published: January 23, 2017

doi:10.5539/jmr.v9n1p84 URL: http://dx.doi.org/10.5539/jmr.v9n1p84

\begin{abstract}
In this paper, the most basic idea is to apply the viscosity approximation method to study the split feasibility problem (SFP), we will be in the infinite-dimensional Hilbert space to study the problem. We defined $x_{0} \in C$ as arbitrary and $x_{n+1}=\left(1-\alpha_{n}\right) P_{C}\left(I-\lambda_{n} A^{*}\left(I-P_{Q}\right) A\right) x_{n}+\alpha_{n} f\left(x_{n}\right)$, for $n \geq 0$, where $\left\{\alpha_{n}\right\} \subset(0,1)$. Under the proper control conditions of some parameters, we show that the sequence $\left\{x_{n}\right\}$ converges strongly to a solution of SFP. The results in this paper extend and further improve the relevant conclusions in Deepho (Deepho, J. \& Kumam, P., 2015).
\end{abstract}

Keywords: split feasibility problem, viscosity approximation method, strong convergence

Mathematics Subject Classifications(2010): 47H05, 47H09, 47H20

\section{Introduction}

In recent years, a large number of scholars have done a lot of meaningful research on the split feasibility problem (SFP), because the problem in signal processing and linear constrained optimization problems such as the feasible solution plays an important role (Censor, Y., et al, 2006; Byrne, C., 2002; Byrne, C., 2004.; Yang, Q., 2004.; Qu, B. \& Xiu, N., 2005.; Xu, H. K., 2006.; Xu, H. K., 2010). In 1994,the SFP was first introduced by Censor and Elfving (Censor, Y. \& Elfving, T., 1994), which is to find a point $x^{*}$ satisfying the property:

$$
x^{*} \in C, A x^{*} \in Q,
$$

where $C$ and $Q$ be nonempty closed convex subsets of the real Hilbert spaces $H_{1}$ and $H_{2}, A: H_{1} \rightarrow H_{2}$ be a bounded linear operator.

In order to find the solution of the problem SFP (1), many authors have proposed a variety of algorithms, it is worth noting that Byrne (Byrne, C., 2002) proposed the so-called CQ algorithm, the algorithm is this: take an initial point $x_{0} \in H_{1}$ arbitrarily, and define the iterative step as

$$
x_{n+1}=P_{C}\left(x_{n}-\lambda A^{*}\left(I-P_{Q} A x_{n}\right), n \geq 0,\right.
$$

Where $0<\lambda<2 / \rho\left(A^{*} A\right)$ and $P_{C}$ denotes the projector onto $C$ and $\rho\left(A^{*} A\right)$ is the spectral radius of the self-adjoint operator $A^{*} A, I$ denotes the identity operator.Then the sequence $\left\{x_{n}\right\}_{n \geq 0}$ generated by (2) converges strongly to a solution of SFP whenever $H_{1}$ is finite-dimensional and whenever there exists a solution to $\operatorname{SFP}(1)$.

By Byrne's CQ algorithm and Xu's viscosity approximatiom method (Xu, H. K., 2004), In 2015, Deepho and Kumam (Deepho, J. \& Kumam, P., 2015) proposed the following algorithm:

$$
x_{n+1}=\left(1-\alpha_{n}\right) P_{C}\left(I-\lambda A^{*}\left(I-P_{Q}\right) A\right) x_{n}+\alpha_{n} f\left(x_{n}\right), n \geq 1,
$$

where $\left\{\alpha_{n}\right\} \in(0,1), 0<\lambda<2 /\|A\|^{2}, f: C \rightarrow C$ is a contraction on $\mathrm{C}$, and they proved that when the parameter $\left\{\alpha_{n}\right\}$ satisfied certain conditions ,then the algorithm (3) is strong converges to a solution of SFP(1). In this paper, we study the following more general algorithm which generates a sequence according to the recursive formula:

$$
x_{n+1}=\left(1-\alpha_{n}\right) P_{C}\left(I-\lambda_{n} A^{*}\left(I-P_{Q}\right) A\right) x_{n}+\alpha_{n} f\left(x_{n}\right), n \geq 0,
$$

And we will show that the sequence $\left\{x_{n}\right\}_{n \geq 0}$ defined by (4) strongly converges to a solution of SFP(1).

\section{Preliminaries}

Throughout this paper, we always assumes that $H_{1}$ and $H_{2}$ are two real Hilbert spaces with inner product $\langle\cdot\rangle$ and norm $\|\cdot\|$, we use $\Omega$ to denote the solution set of $\operatorname{SFP}(1)$, that is $\Omega=\{x \in C: A x \in Q\}=C \cap A^{-1} Q$, The notation: $\rightarrow$ denotes 
weak convergence and $\rightarrow$ denotes strong convergence. Below we first list the definitions and theorems to be used in this paper.

Definition 2.1. Assume $H$ is a real Hilbert space. Let $T: H \rightarrow H$ be the nonlinear operators,

(i) ) $T$ is nonexpansive if $\|T x-T y\| \leq\|x-y\|$, for all $x, y \in H$;

(ii) $T$ is firmly nonexpansive if $\langle x-y, T x-T y\rangle \geq\|T x-T y\|^{2}, x, y \in H$;

(iii) $T$ is $v$ - inverse strongly monotone ( $v-$ ism), with $v>0$, if

$$
\langle x-y, T x-T y\rangle \geq v\|T x-T y\|^{2}, \quad x, y \in H .
$$

(iv) $T$ is averaged if $T=(1-\alpha) I+\alpha S$ £where $\alpha \in(0,1) £$ and $S: H \rightarrow H$ is nonexpansive. In this case, we also say that $T$ is $\alpha$-averaged. Thus firmly nonexpansive mappings (in particular ,the projections ) is $\frac{1}{2}-$ averaged mappings.

Definition 2.2. An operator $T: H \rightarrow H$ is called oriented operator if $F i x(T) \neq \Phi$, and

$$
\langle z-T x, x-T x\rangle \leq 0, \quad x \in H .
$$

In fact, we know that the oriented operator also contains firmly nonexpansive operator. The following is a useful characterization of projections.

Proposition 2.1 Given $x \in H$ and $z \in C$. Then $z=P_{C} x$ if and only if

$$
<x-z, y-z>\leq 0, \forall y \in C \text {. }
$$

We collect some basic properties of averaged mappings and inverse strongly monotone operators in the following lemma.

Lemma 2.1 (Qu, B. \& Xiu, N., 2005; Xu, H. K., 2011) Let $T: H \rightarrow H$ be a given mapping.

(i) ) $T$ is nonexpansive if and only if the complement $I-T$ is $\frac{1}{2}-i s m$;

(ii)If $T$ is $v-i s m$, and $\gamma>0$, then $\gamma T$ is $\frac{v}{\gamma}-i s m$;

(iii) $T$ is averaged if and only if the complement $I-T$ is $v-i s m$ for some $v>\frac{1}{2}$. Indeed, for $\alpha \in(0,1), T$ is $\alpha-$ averaged if and only if $I-T$ is $\frac{1}{2 \alpha}-i s m$.

(iv) If $T_{1}$ is $\alpha_{1}$ - averaged and $T_{2}$ is $\alpha_{2}$ - is averaged, where $\alpha_{1}, \alpha_{2} \in(0,1)$, then the composite $T_{1} T_{2}$ is $\alpha$ - averaged, where $\alpha=\alpha_{1}+\alpha_{2}-\alpha_{1} \alpha_{2}$.

Lemma 2.2 (Wang, F. H. \& Xu., H. K., 2010) Suppose $C \cap A^{-1} Q \neq \Phi$. Let $U=I-\lambda A^{*}\left(I-P_{Q}\right) A$, where $0<\lambda<$ $2 / \rho\left(A^{*} A\right)$, and $\rho\left(A^{*} A\right)$ is the spectral radius of the self-adjoint operator $A^{*} A$.

(i) $U$ is an averaged mapping; namely, $U=(1-\beta) I+\beta V$, where $\beta \in(0,1)$ is a constant and $V: H_{1} \rightarrow H_{1}$ is nonexpansive;

(ii) $\operatorname{Fix}(U)=A^{-1} Q$; consequently, $\operatorname{Fix}\left(P_{C} U\right)=\operatorname{Fix}\left(P_{C}\right) \cap \operatorname{Fix}(U)=\Omega=C \cap A^{-1} Q$.

Lemma 2.3 (Geobel, K. \& Kirk, W. A., 1990) Let $H$ be a Hilbert space and let $C$ be a nonempty closed convex subset of $H$, let $T: C \rightarrow C$ is a nonexpansive mapping with $F i x(T) \neq \Phi$, Suppose that $\left\{x_{n}\right\} \subset C$ is such that $x_{n} \rightarrow z$ and $x_{n}-T x_{n} \rightarrow 0$. Then $z \in F(T)$.

Lemma 2.4 (Cui, H. H., Su, M. L. \& Wang, F. H., 2013) Suppose $A: H_{1} \rightarrow H_{2}$ be a bounded linear operator, and $T: H_{2} \rightarrow H_{2}$ is an oriented operator, Let $V_{\lambda}=I-\lambda A^{*}(I-T) A$, where $0<\lambda<\frac{2}{\|A\|^{2}}$. If $A^{-1}(F i x(T)) \neq \Phi$, then

$$
\left\|V_{\lambda} x-z\right\|^{2} \leq\|x-z\|^{2}-\frac{2-\lambda\|A\|^{2}}{\lambda\|A\|^{2}}\left\|V_{\lambda} x-x\right\|^{2}
$$

where $z \in A^{-1}(F i x(T))$ and $x \in H_{1}$.

Lemma 2.5 (Mainge, P. E. \& Maruster, S. 2011) Let $\left\{a_{n}\right\}$ be a nonnegative real sequence satisfying

$$
a_{n+1} \leq\left(1-\gamma_{n}\right) a_{n}+\delta_{n}
$$

Where $\left\{\gamma_{n}\right\} \subset(0,1)$, and $\left\{\delta_{n}\right\}$ is a sequences such that

(i) $\sum_{n=0}^{\infty} \gamma_{n}=\infty$;

(ii) $\limsup _{n \rightarrow \infty} \delta_{n} / \gamma_{n} \leq 0$ or $\sum_{n=0}^{\infty}\left|\delta_{n}\right|<\infty$.

Then $\lim _{n \rightarrow \infty} a_{n}=0$. 


\section{NSTL Condition}

Let $C$ be a nonempty closed convex subset of a real Hilbert space $H$. Motivated by Nakajo, Shimoji and Takahashi (Takahashi, W., 2009), we give the following definition: Let $T_{n}$ be families of nonexpansive mappings of $C$ into itself such that $\cap_{n=1}^{\infty} F\left(T_{n}\right) \neq \Phi$, where $F\left(T_{n}\right)$ is the set of all fixed points of $T_{n}$. Then $T_{n}$ is said to be satisfy NSTL-condition if for each bounded sequence $\left\{z_{n}\right\} \subset C$,

$$
\lim _{n \rightarrow \infty}\left\|z_{n+1}-T_{n} z_{n}\right\|=0
$$

implies that

$$
\lim _{n \rightarrow \infty}\left\|z_{n}-T_{n} z_{n}\right\|=0
$$

\section{Main Results}

Theorem 3.1 Suppose the SFP(1) is consistent and $0<\lambda^{\prime}<\lambda_{n}<\lambda^{\prime \prime}<\frac{2}{\|A\|^{2}}$. Let $C$ be a nonempty closed convex subset of a real Hilbert space $H_{1}$. Let $f: C \rightarrow C$ be a contraction with constant $\rho \in(0,1)$. Take an initial guess $x_{0} \in H_{1}$ arbitrarily, and we define the sequence $\left\{x_{n}\right\}$ by

$$
x_{n+1}=\left(1-\alpha_{n}\right) P_{C}\left(I-\lambda_{n} A^{*}\left(I-P_{Q}\right) A\right) x_{n}+\alpha_{n} f\left(x_{n}\right), n \geq 0,
$$

where

$\left\{\alpha_{n}\right\} \subset(0,1)$ such that

$$
\begin{gathered}
\text { (C1) } \lim _{n \rightarrow \infty} \alpha_{n}=0 ; \\
(\mathrm{C} 2) \sum_{n=0}^{\infty} \alpha_{n}=\infty ; \\
(\mathrm{C} 3) \sum_{n=0}^{\infty}\left|\alpha_{n+1}-\alpha_{n}\right|<\infty ;
\end{gathered}
$$

Then the sequence $\left\{x_{n}\right\}$ generated by algorithm(7) converges strongly to $\tilde{x} \in \Omega$, where $\tilde{x}=P_{\Omega} f(\tilde{x})$.

Proof. The proof of the process will be divided into four steps. First we show that the sequence $\left\{x_{n}\right\}$ is bounded. For our convenience, we take $T_{n}=P_{C}\left(I-\lambda_{n} A^{*}\left(I-P_{Q}\right) A\right)$. We assume $\bigcap_{n=1}^{\infty} F\left(T_{n}\right) \neq \Phi$ and $T_{n}$ satisfy NSTL condition. By lemma 2.2, we know that $\bigcap_{n=1}^{\infty} F\left(T_{n}\right)$ is a solution of $\operatorname{SFP}(1)$.Now, we note that the condition $0<\lambda^{\prime}<\lambda_{n}<\lambda^{\prime \prime}<\frac{2}{\|A\|^{2}}$ implies that the operator $P_{C}\left(I-\lambda_{n} A^{*}\left(I-P_{Q}\right) A\right)$ is averaged. Since $I-P_{Q}$ is firmly nonexpansive mappings and so is $\frac{1}{2}$-averaged, which is 1 -ism. Also observe that $A^{*}\left(I-P_{Q}\right) A$ is $\frac{1}{\|A\|^{2}}$-ism so that $\lambda_{n} A^{*}\left(I-P_{Q}\right) A$ is $\frac{1}{\|A\|^{2}}$-ism. Further, from the fact that $I-\lambda_{n} A^{*}\left(I-P_{Q}\right) A$ is $\frac{1}{\lambda_{n}\|A\|^{2}}$ averaged and $P_{C}$ is $\frac{1}{2}$-averaged, by lemma 2.1 , we may obtain that $P_{C}\left(I-\lambda_{n} A^{*}\left(I-P_{Q}\right) A\right)$ is $\mu_{n}$ - averaged, where

$$
\mu_{n}=\frac{1}{2}+\frac{\lambda_{n}\|A\|^{2}}{2}-\frac{1}{2} \frac{\lambda_{n}\|A\|^{2}}{2}=\frac{2+\lambda_{n}\|A\|^{2}}{4} \in(0,1),
$$

This implies that $T_{n}=\mu_{n} I+\left(1-\mu_{n}\right) S$, where $\mu_{n}=\frac{2+\lambda_{n}\|A\|^{2}}{4} \in(0,1)$ for some nonexpansive mappings S. Note that $T_{n}$ is also nonexpansive mappings, then for $p \in \bigcap_{n=1}^{\infty} F\left(T_{n}\right) \in \Omega$, we have $T_{n} p=p$, then

$$
\begin{aligned}
\left\|x_{n+1}-p\right\| & \leq\left(1-\alpha_{n}\right)\left\|T_{n} x_{n}-p\right\|+\alpha_{n} \| f\left(x_{n}-p \|\right. \\
& \leq\left(1-\alpha_{n}\right)\left\|x_{n}-p\right\|+\alpha_{n}\left(\left\|f\left(x_{n}\right)-f(p)\right\|+\|f(p)-p\|\right) \\
& \leq\left(1-\alpha_{n}\right)\left\|x_{n}-p\right\|+\alpha_{n}\left(\rho\left\|x_{n}-p\right\|+\|f(p)-p\|\right) \\
& =\left(1-(1-\rho) \alpha_{n}\right)\left\|x_{n}-p\right\|+\alpha_{n}\|f(p)-p\| \\
& \leq \max \left\{\left\|x_{n}-p\right\|, \frac{1}{1-\rho}\|f(p)-p\|\right\},
\end{aligned}
$$

By induction

$$
\left\|x_{n}-p\right\| \leq \max \left\{\left\|x_{0}-p\right\|, \frac{1}{1-\rho}\|f(p)-p\|\right\}, n \geq 0,
$$


So $\left\{x_{n}\right\}$ is bounded, we also have that $\left\{T_{n} x_{n}\right\}$ and $\left\{f\left(x_{n}\right)\right\}$ are bounded.

Next, we claim that

$$
\lim _{n \rightarrow \infty}\left\|x_{n}-T_{n} x_{n}\right\|=0,
$$

Indeed, by the definition of the (7), that is $x_{n+1}=\left(1-\alpha_{n}\right) T_{n} x_{n}+\alpha_{n} f\left(x_{n}\right)$, so $\lim _{n \rightarrow \infty}\left\|x_{n+1}-T_{n} x_{n}\right\|=\alpha_{n}\left\|T_{n} x_{n}-f\left(x_{n}\right)\right\|$, By the condition (C1), we have $\lim _{n \rightarrow \infty}\left\|x_{n+1}-T_{n} x_{n}\right\|=0$. This together with the NSTL condition, Thus, (8) is clearly established.

Next, we will show that

$$
\limsup _{n \rightarrow \infty}\left\langle\tilde{x}-x_{n}, \tilde{x}-f(\tilde{x})\right\rangle \leq 0
$$

Indeed take a subquence $\left\{x_{n_{k}}\right\}$ of $\left\{x_{n}\right\}$ such that

$$
\limsup _{n \rightarrow \infty}\left\langle\tilde{x}-x_{n}, \tilde{x}-f(\tilde{x})\right\rangle=\limsup _{n \rightarrow \infty}\left\langle\tilde{x}-x_{n_{k}}, \tilde{x}-f(\tilde{x})\right\rangle
$$

We may assume that $x_{n_{k}} \rightarrow \bar{x}$. It follows from Lemma 2.3 and $\left\|T_{n} x_{n}-x_{n}\right\| \rightarrow 0$ that is $\bar{x} \in \operatorname{Fix}\left(T_{n}\right) \in \Omega$. Hence from Lemma 2.3, we obtain

$$
\limsup _{n \rightarrow \infty}\left\langle\tilde{x}-x_{n}, \tilde{x}-f(\tilde{x})\right\rangle=\langle\tilde{x}-\bar{x}, \tilde{x}-f(\tilde{x})\rangle \leq 0
$$

Finally, we will show that $x_{n} \rightarrow \tilde{x}$ in norm. It follows from Lemma 2.4, we obtain

$$
\begin{aligned}
\left\|T_{n} x_{n}-\tilde{x}\right\|^{2} & \leq\left\|x_{n}-\tilde{x}\right\|^{2}-\frac{2-\lambda_{n}\|A\|^{2}}{\lambda_{n}\|A\|^{2}}\left\|T_{n} x_{n}-x_{n}\right\|^{2} \\
& \leq\left\|x_{n}-\tilde{x}\right\|^{2}-\frac{2-\lambda^{\prime \prime}\|A\|^{2}}{\lambda^{\prime \prime}\|A\|^{2}}\left\|T_{n} x_{n}-x_{n}\right\|^{2}
\end{aligned}
$$

Thus, we have

$$
\begin{aligned}
\left\|x_{n+1}-\tilde{x}\right\|^{2} & \doteq\left(1-\alpha_{n}\right)\left\|\left(T_{n} x_{n}-\tilde{x}\right)+\alpha_{n}\left(f\left(x_{n}\right)-\tilde{x}\right)\right\|^{2} \\
& \doteq\left(1-\alpha_{n}\right)^{2}\left\|T_{n} x_{n}-\tilde{x}\right\|^{2}+\alpha_{n}^{2}\left\|f\left(x_{n}\right)-\tilde{x}\right\|^{2}+2 \alpha_{n}\left(1-\alpha_{n}\right)\left\langle T_{n} x_{n}-\tilde{x}, f\left(x_{n}\right)-\tilde{x}\right\rangle \\
& \leq\left(1-\alpha_{n}\right)^{2}\left[\left\|x_{n}-\tilde{x}\right\|^{2}-\frac{2-\lambda^{\prime \prime}\|A\|^{2}}{\lambda^{\prime \prime}\|A\|^{2}}\left\|T_{n} x_{n}-x_{n}\right\|^{2}\right] \\
& +\alpha_{n}^{2}\left\|f\left(x_{n}\right)-\tilde{x}\right\|^{2}+2 \alpha_{n}\left(1-\alpha_{n}\right)\left\langle T_{n} x_{n}-\tilde{x}, f\left(x_{n}\right)-\tilde{x}\right\rangle \\
& \leq\left(1-\alpha_{n}\right)^{2}\left\|x_{n}-\tilde{x}\right\|^{2}-\frac{\left(1-\alpha_{n}\right)^{2}\left(2-\lambda^{\prime \prime}\|A\|^{2}\right)}{\lambda^{\prime \prime}\|A\|^{2}}\left\|T_{n} x_{n}-x_{n}\right\|^{2} \\
& +\alpha_{n}^{2}\left\|f\left(x_{n}\right)-\tilde{x}\right\|^{2}+2 \alpha_{n}\left(1-\alpha_{n}\right)\left\langle T_{n} x_{n}-\tilde{x}, f\left(x_{n}\right)-f(\tilde{x})\right\rangle+2 \alpha_{n}\left(1-\alpha_{n}\right)\left\langle T_{n} x_{n}-\tilde{x}, f(\tilde{x})-\tilde{x}\right\rangle \\
& \leq\left(1-\alpha_{n}\right)^{2}\left\|x_{n}-\tilde{x}\right\|^{2}-\frac{\left(1-\alpha_{n}\right)^{2}\left(2-\lambda^{\prime \prime}\|A\|^{2}\right)}{\lambda^{\prime \prime}\|A\|^{2}}\left\|T_{n} x_{n}-x_{n}\right\|^{2} \\
& +\alpha_{n}^{2}\left\|f\left(x_{n}\right)-\tilde{x}\right\|^{2}+2 \rho \alpha_{n}\left(1-\alpha_{n}\right)\left\|x_{n}-\tilde{x}\right\|^{2}+2 \alpha_{n}\left(1-\alpha_{n}\right)\left\langle T_{n} x_{n}-\tilde{x}, f(\tilde{x})-\tilde{x}\right\rangle \\
& \doteq\left[1-\left(2 \alpha_{n}-\alpha_{n}^{2}-2 \rho \alpha_{n}\left(1-\alpha_{n}\right)\right)\right]\left\|x_{n}-\tilde{x}\right\|^{2}-\frac{\left(1-\alpha_{n}\right)^{2}\left(2-\lambda^{\prime \prime}\|A\|^{2}\right)}{\lambda^{\prime \prime}\|A\|^{2}}\left\|T_{n} x_{n}-x_{n}\right\|^{2} \\
& +\alpha_{n}^{2}\left\|f\left(x_{n}\right)-\tilde{x}\right\|^{2}+2 \alpha_{n}\left(1-\alpha_{n}\right)\left\langle T_{n} x_{n}-\tilde{x}, f(\tilde{x})-\tilde{x}\right\rangle \\
& \doteq\left(1-\gamma_{n}\right)\left\|x_{n}-\tilde{x}\right\|^{2}+\gamma_{n} \delta_{n},
\end{aligned}
$$

That is

$$
\left\|x_{n+1}-\tilde{x}\right\|^{2} \leq\left(1-\gamma_{n}\right)\left\|x_{n}-\tilde{x}\right\|^{2}+\gamma_{n} \delta_{n}
$$

where

$$
\begin{gathered}
\gamma_{n} \doteq 2 \alpha_{n}-\alpha_{n}^{2}-2 \rho \alpha_{n}\left(1-\alpha_{n}\right), \\
\delta_{n} \doteq-\frac{\left(1-\alpha_{n}\right)^{2}\left(2-\lambda^{\prime \prime}\|A\|^{2}\right)}{\left[2 \alpha_{n}+\alpha_{n}^{2}-2 \rho \alpha_{n}\left(1-\alpha_{n}\right)\right] \lambda^{\prime \prime}\|A\|^{2}}\left\|T_{n} x_{n}-x_{n}\right\|^{2}+\frac{\alpha_{n}\left\|f\left(x_{n}\right)-z\right\|^{2}}{2-\alpha_{n}-2 \rho\left(1-\alpha_{n}\right)}+\frac{2\left(1-\alpha_{n}\right)}{2-\alpha_{n}-2 \rho\left(1-\alpha_{n}\right)}\left\langle T_{n} x_{n}-\tilde{x}, f(\tilde{x})-\tilde{x}\right\rangle
\end{gathered}
$$


It is easily seen from (C1),(C2),(8) and (9) that

$$
\gamma_{n} \rightarrow 0, \sum_{n=1}^{\infty} \gamma_{n}=\infty, \limsup _{n \rightarrow \infty} \delta_{n} \leq 0
$$

Finally apply lemma 2.5 to (10), we conclude that $\left\|x_{n}-\tilde{x}\right\| \rightarrow 0$.

Corollary 3.1 (Deepho, J. \& Kumam, P., 2015) Suppose the SFP(1.1) is consistent and $0<\lambda<\frac{2}{\|A\|^{2}}$. Let $C$ be a nonempty closed convex subset of a real Hilbert space $H_{1}$. Let $f: C \rightarrow C$ be a contraction with constant $\rho \in(0,, 1)$.Take an initial guess $x_{0} \in H_{1}$ arbitrarily,and we define the sequence $\left\{x_{n}\right\}$ by

$$
x_{n+1}=\left(1-\alpha_{n}\right) P_{C}\left(I-\lambda A^{*}\left(I-P_{Q}\right) A\right) x_{n}+\alpha_{n} f\left(x_{n}\right), n \geq 0,
$$

where $\left\{\alpha_{n}\right\} \subset(0,1)$ such that

(1) $\lim _{n \rightarrow \infty} \alpha_{n}=0$;

(2) $\sum_{n=0}^{\infty} \alpha_{n}=\infty$;

(3) $\sum_{n=0}^{\infty}\left|\alpha_{n+1}-\alpha_{n}\right|<\infty$;

Then the sequence $x_{n}$ generated by algorithm(11) converges strongly to $\tilde{x}$, where $\tilde{x}$ is the unique solution of the variational inequality

$$
\langle(I-f) \tilde{x}, x-\tilde{x}\rangle \geq 0, \quad x \in \Omega .
$$

Remark1: Let $\lambda_{n}=\lambda$ in algorithm(3.1), Thus it follows directly from Theorem 3.1 that the conclusion holds. The proof is complete. It is worth noting that our method of proof is different from the method of (Deepho, J. \& Kumam, P., 2015).

\section{References}

Byrne, C. (2002). Iterative oblique projection onto convex sets and the split feasibility problem. Inverse Problems., 18, 441-453. http://dx.doi.org/10.1088/0266-5611/18/2/310

Byrne, C. (2004). A unified treatment of some iterative algorithms in signal processing and image reconstruction. Inverse Problems., 20, 103-120. http://dx.doi.org/10.1088/0266-5611/20/1/006

Censor, Y., Bortfeld, T., Martin, B., \& Trofimov, A. (2006). A unified approach for inversion problems in intensity modulated radiation therapy. Phys. Med. Biol., 51,2253-2365. http://dx.doi.org/10.1088/0031-9155/51/10/001

Censor, Y., \& Elfving, T. (1994). A multiprojection algorithm using Bregman projections in a product space. Numer. Algorithms., 8, 221-239. http://dx.doi.org/10.1007/BF02142692

Cui, H. H., Su, M. L., \& Wang, F. H. (2013). Damped projection method for the split common fixed point problems. Journal of Inequalities and Applications 2013, 123. http://dx.doi.org/10.1186/1029-242x-2013-123

Deepho, J., \& Kumam, P. (2015). A viscosity approximation method for the split feasibility problem. Transactions on Engineering Technologies, 69-77. http://dx.doi.org/10.1007/978-94-017-9588-3-6.

Geobel, K., \& Kirk, W. A. (1990). Topics in Metric Fixed Point Theory[M]. Cambridge: Cambridge University Press.

Mainge, P. E., \& Maruster, S. (2011). Convergence in norm of modified Krasnoselski-Mann iterations for fixed points of demicontractive mappings. Applied Mathematics and Computation, 217, 9864-9874. http://dx.doi.org/10.1016/j.amc.2011.04.068

Qu, B., \& Xiu, N. (2005). A note on the CQ algorithm for the split feasibility problem. Inverse Problems., 21, 1655-1665. http://dx.doi.org/10.1088/0266-5611/21/5/009

Takahashi, W. (2009). Viscosity approximation methods for countable families of nonexpansive mappings in Banach spaces. Nonlinear Analysis: Theory, Method and Applications, 70,719-734. http://dx.doi.org/10.1016/j.na.2008.01.005

Wang, F. H., \& Xu., H. K. (2010). Approximating curve and strong convergence of the Cqalgorithm for the split feasibility problem. Journal of Inequalities and Applications. 2010, 1-13. http://dx.doi.org/10.1155/2010/102085

$\mathrm{Xu}, \mathrm{H}$. K. (2006). A variable Krasnosel'skii-Mann algorithm and the multiple-set split feasibility problem. Inverse Problems, 22, 2021-2034. http://dx.doi.org/10.1088/0266-5611/22/6/007

$\mathrm{Xu}, \mathrm{H}$. K. (2010). Iterative methods for the split feasibility problem in infinite-dimensional Hilbert spaces. Inverse Problems, 26, 105018. http://dx.doi.org/10.1088/0266-5611/26/10/105018 
Xu, H. K. (2004). Viscosity approximation methods for nonexpansive mapping. J. Math. Anal. Appl., 298, 279-291. http://dx.doi.org/10.1016/j.jmaa.2004.04.059

Xu, H. K. (2011). Averaged Mappings and the Gradient-Projection Algorithm. J. Optim. Theory . Appl, 150, 360-378. http://dx.doi.org/10.1007/s10957-011-9837-z

Yang, Q. (2004). The relaxed CQ algorithm solving the split feasibility problem. Inverse Problems, 20, 1261-1266. http://dx.doi.org/10.1088/0266-5611/20/4/014

\section{Copyrights}

Copyright for this article is retained by the author(s), with first publication rights granted to the journal.

This is an open-access article distributed under the terms and conditions of the Creative Commons Attribution license (http://creativecommons.org/licenses/by/4.0/). 